\title{
Esporotricose e seu Polimorfismo Clínico: Um Caso com Lesões Ulceradas na Região Centro Facial em Paciente Adulto
}

Victor Bechara de Castro, Carolina Portela, Marina Câmara de Oliveira, Daniel Lago Obadia, Alexandre Carlos Gripp

Serviço de Dermatologia, HUPE/UERJ- Hospital Universitário Pedro Ernesto, Rio de Janeiro, Portugal

RESUMO - Esporotricose é a micose subcutânea mais comum no mundo, causada por fungos dimórficos e geofílicos, das espécies Sporothrix spp. A forma linfo cutânea é a apresentação clinica mais comum e o acometimento facial é mais prevalente na faixa etária pediátrica, devido à baixa estatura e ao hábito de brincar com felinos próximo a face. Nesse relato de caso, uma paciente do sexo feminino, com diagnóstico prévio de rosácea, residente na cidade do Rio de Janeiro, área epidêmica da doença, apresentou lesões ulceradas no dorso nasal, lábio superior e glabela, diagnosticada tardiamente como esporotricose.

PALAVRAS-CHAVE - Dermatoses Faciais; Esporotricose; Micose; Rosácea; Úlcera Cutânea.

\section{Sporotrichosis and its Clinical Polymorphism: Centrofacial Ulcerated Lesions in an Adult Patient}

\begin{abstract}
Sporotrichosis is the most frequent subcutaneous mycosis worldwide, caused by a geophilic and dimorphic fungus of the species Sporothrix spp. Lymphocutaneous form is the most common clinical presentation and facial involvement is more prevalent in pediatric patients due to low stature and leisure habits of holding cats close to the face. In this case report, a female patient, with previous diagnosis of rosacea, resident in Rio de Janeiro, an epidemic region of the disease, presented ulcerated lesions on dorsal nasal, upper lip and glabella regions, diagnosed lately as sporotrichosis
\end{abstract}

KEYWORDS - Facial Dermatoses; Mycoses; Rosacea; Skin Ulcer; Sporotrichosis.

\section{INTRODUÇÃO}

Esporotricose é uma micose cutânea e subcutânea, crónica ou subaguda, causada por fungos dimórficos, geofílicos, das espécies Sporothrix spp.' Sua transmissão ocorre após trauma, comumente através de contato com galhos, restos de madeira ou arranhaduras e/ou mordedura de felinos infectados. Sua apresentação clínica é diversa, manifestando-se, principalmente, nas formas linfo cutânea e cutânea fixa. Membros superiores e face são mais comumente acometidos na faixa etária pediátrica. ${ }^{2}$

\section{RELATO DE CASO}

Mulher, 56 anos, moradora de área urbana do Rio de Janeiro, com diagnóstico prévio de rosácea, relatou lesão pápulo-eritematosa do dorso nasal há aproximadamente um ano que em poucos dias aumentou progressivamente e surgiu de lesão semelhante acima do lábio superior e glabela. Procurou atendimentos médicos, realizando ciclos de antibioticoterapia e corticoterapia tópica, sem sucesso. Após seis meses do início do quadro, a lesão nasal evoluiu com ulceração e sangramento, sendo indicada biópsia, cujo resultado foi compatível com paracoccidioidomicose, sendo então encaminhada ao nosso serviço.

Ao exame físico apresentava úlcera nasal com bordas bem delimitadas e hiperemiadas e uma úlcera de menor tamanho acima do lábio superior à esquerda e região glabelar (Fig. 1). De história epidemiológica, referia gatos na vizinhança, mas negou contato direto com os animais.

Embora a história epidemiológica não fosse conclusiva, suspeitou-se de esporotricose, sendo realizada nova biópsia da lesão nasal, exame micológico direto com cultura para fungos e sorologia para esporotricose, $\lg G$ SsCBF (técnica
Correspondência: Victor Bechara de Castro Instituição: HUPE/UERJ- Hospital Universitário Pedro Ernesto Boulevard 28 de setembro,77- Rio de Janeiro

Email: becharavic@yahoo.com.br

DOI: https://dx.doi.org/10.29021/spdv.76.1.805
Recebido/Received

14 Setembro/September 2017

Aceite/Accepted

19 Dezembro/December 2017 


\section{Caso Clínico}

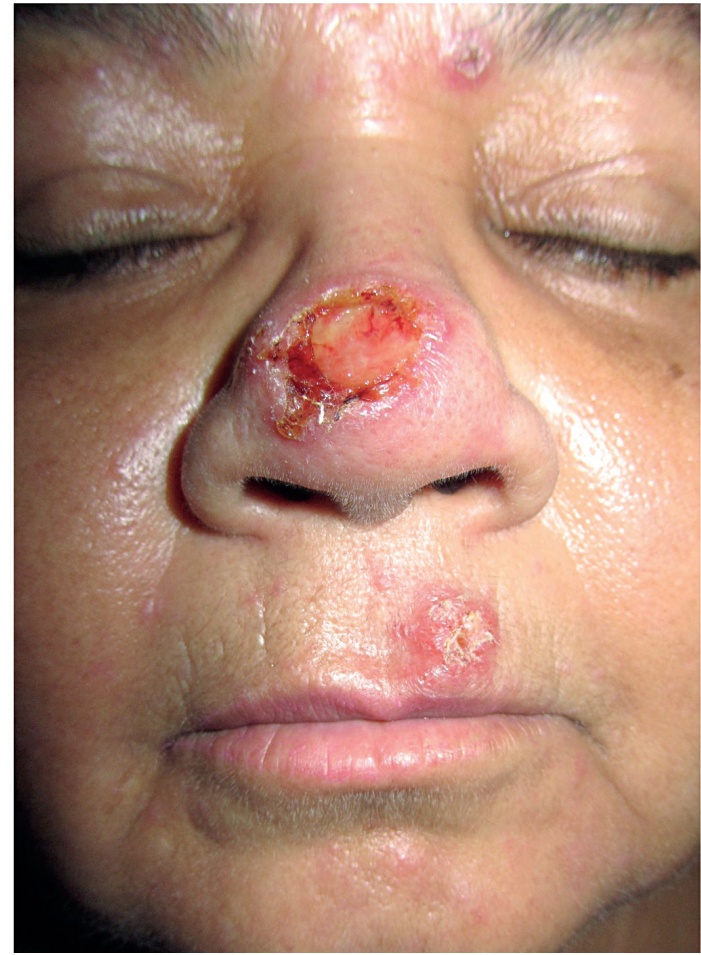

Figura 1 - Lesões ulcero-crostrosas, com bordas bem delimitadas eritematosas, com diâmetros variando entre 0,4 a 1,5 cm em seu maior eixo, nas regiões supra labial a esquerda, dorso nasal e glabela.

ELISA, desenvolvida no Hospital Universitário Pedro Ernesto, através de método de cromotografia). ${ }^{3} \mathrm{O}$ novo exame histopatológico revelou infiltrado inflamatório difuso, granulomatoso com células polimorfonucleares pela coloração da Hematoxilina-eosina (Fig. 2). Na coloração pelo Grocott observaram-se estruturas fúngicas arrendodadas com brotamento único. O exame micológico direto foi negativo, sendo isolado Sporothrix spp., na cultura para fungos, em meio de

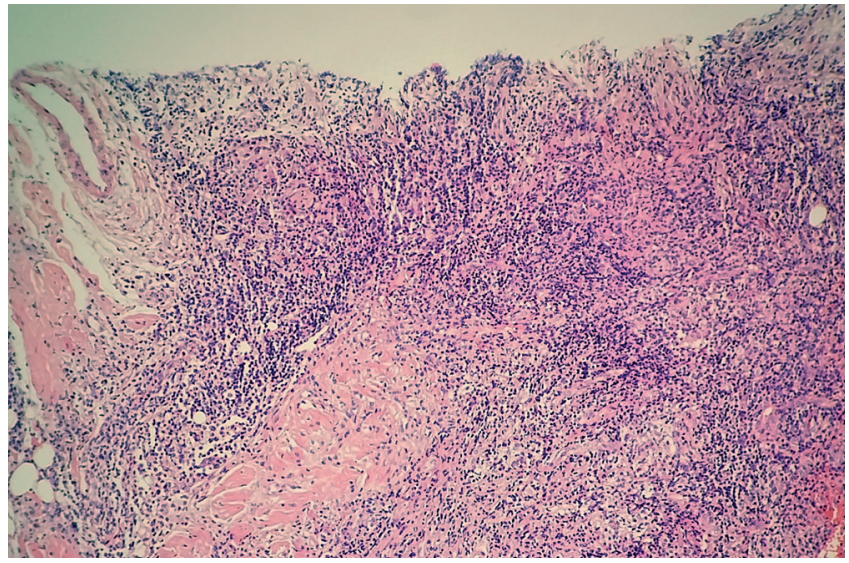

Figure $\mathbf{2}$ - Solução de continuidade com infiltrado inflamatório difuso, granulomatoso com células polimorfonucleares pela coloração da H\&E (aumento 40x)

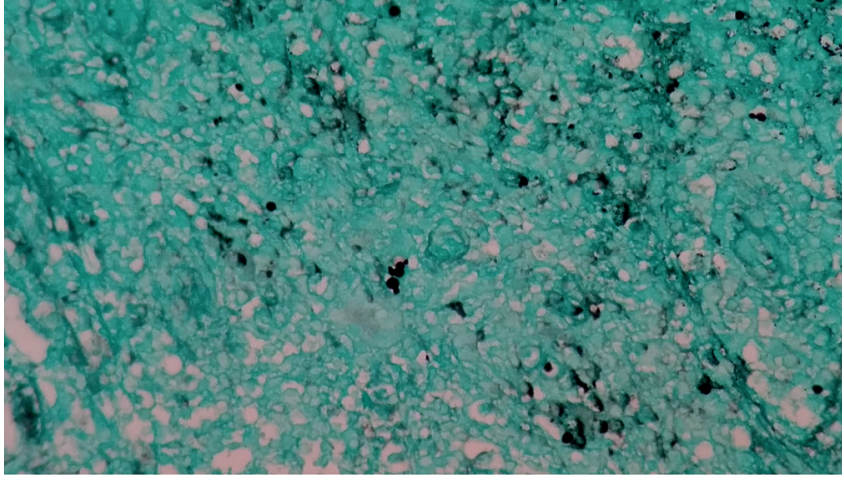

Figure 3 - Em coloração Grocott, notam-se estrututras fungicas arrendondadas com brotamento único.

agar mycosel (Fig. 4). A sorologia para fungos Sporothrix spp. foi negativa.

Foi iniciado itraconazol oral $200 \mathrm{mg} /$ dia, evoluindo com resolução do quadro após sete meses de tratamento, com melhora clínica das lesões, apresentando apenas discreta atrofia e endurecimento das áreas previamente afetadas (Fig. 5). Paciente não apresenta recidiva das lesões após três meses do término do tratamento.

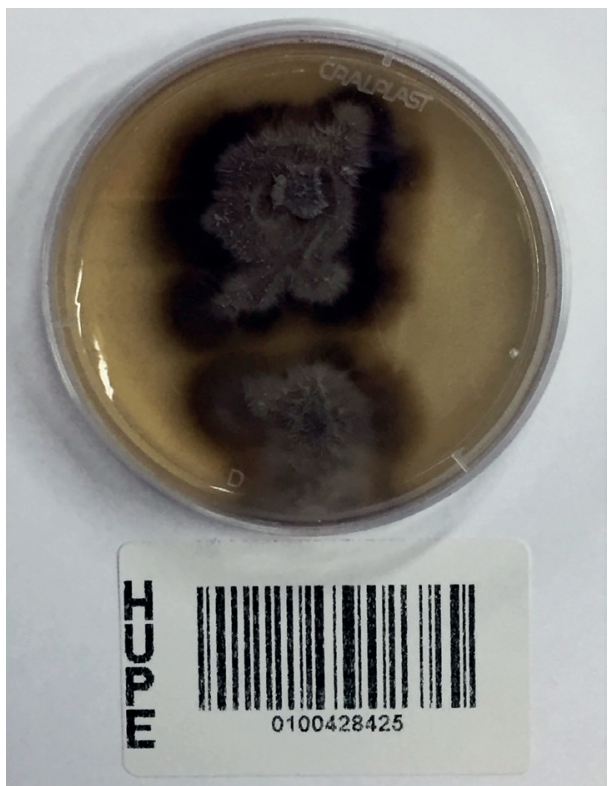

Figura 4 - Colónia membranosa acizentada, espiculada com halo enegrecido.

\section{DISCUSSÃO}

A esporotricose é considerada uma micose polimórfica, atingindo primariamente a pele e o tecido subcutâneo, com comum envolvimento linfático. É causada por fungos dimórficos, geofílicos, do gênero Sporothrix spp., sendo as espécies $S$. brasiliensis, S. globosa, S. luriei e S. schenckii as mais frequentemente envolvidas na infecção. ${ }^{1,4}$ Sua distribuição é 


\section{Caso Clínico}

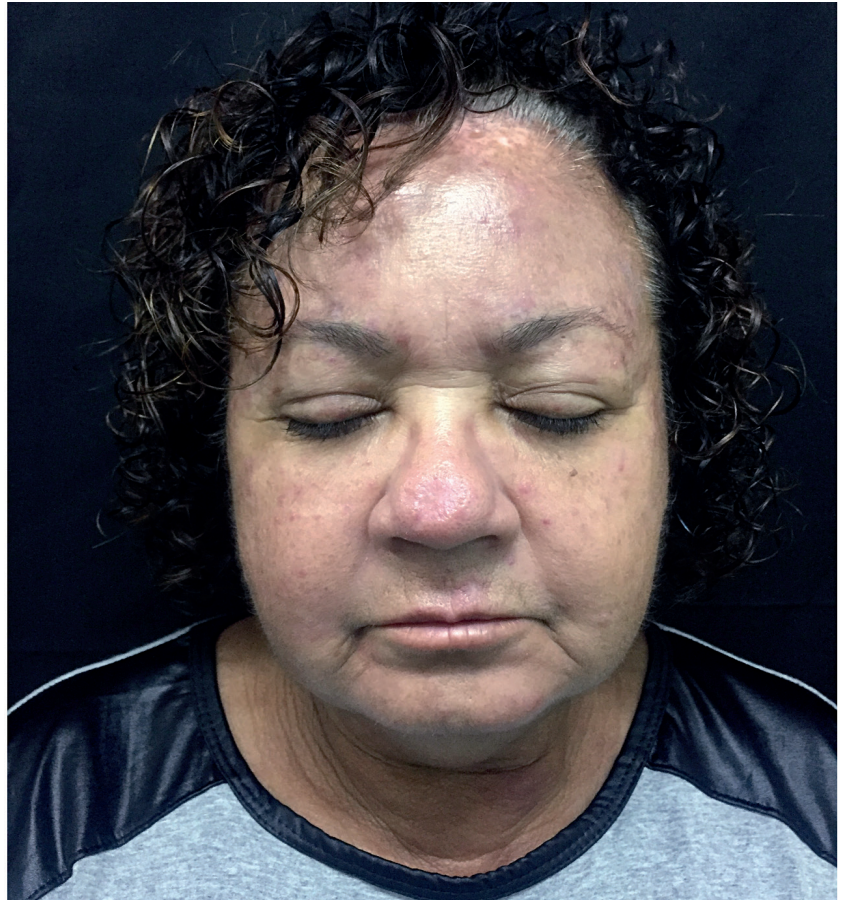

Figura 5 - Após término do tratamento com itraconazol, com melhora clínica, apresentando apenas lesões residuais.

universal, sendo mais comum nas zonas tropicais. Estima-se que na América do Sul a esporotricose seja a micose subcutânea mais frequente, ${ }^{5} \mathrm{com}$ incidência anual de 60 casos em 100000 habitantes.

A transmissão ocorre principalmente através de trauma com materiais contaminados provenientes do solo, como galhos e plantas, sendo por isso classicamente conhecida como a doença do agricultor ou jardineiro. ${ }^{1,4}$ A transmissão zoonótica da esporotricose, através de gatos infectados, responsável pela epidemia atual no estado do Rio de Janeiro, foi descrita já em 1982. ${ }^{\circ}$ Nas últimas décadas, no Brasil, vem aumentando exponencialmente esse tipo de transmissão da doença. De acordo com o Instituto de Pesquisa Evandro Chagas/Fundação Oswaldo Cruz no Rio de Janeiro, Brasil, mais de 4 mil humanos e 3 mil gatos foram infectados com esporotricose no período de 1998 a $2011 .^{7}$ A espécie mais associada a esse tipo de transmissão zoonótica é a $S$. brasiliensis. ${ }^{4}$

A infecção se apresenta com diferentes formas clínicas, variando conforme aspectos de cada hospedeiro, como fatores de imunológicos, profundidade e quantidade do inóculo, além de termo tolerância do agente etiológico.8 A forma cutâneo linfática corresponde a 70\% - 80\% dos casos, apresentando-se como nódulo dérmico, indolor, que evolui para úlcera (conhecida como cancro esporotricótico), com bordas elevadas, centro granulomatoso de fundo limpo, associado a nódulos linfáticos ascendentes, principalmente nos membros superiores de adultos. ${ }^{1,9}$ Já a forma cutânea fixa, apresenta-se como uma lesão única papular, verrucosa ou ulcerada, correspondente ao local de inoculação, sem comprometimento linfático, sendo mais relatado na face de crianças. 9,10 Outras formas foram mais raramente descritas ( $1 \%$ - $2 \%$ dos casos), como as formas sistêmicas que geralmente acometem indivíduos com algum grau de imunossupressão, nomeadamente a forma cutânea disseminada com lesões cutâneas difusas devido a disseminação hematogênica, e as formas osteoarticular, pulmonar e neurológica. 1,8-10

Poucos casos de envolvimento facial, sobretudo da região nasal, são descritos na faixa etária adulta. Em 1981, Bargman reportou um caso de esporotricose nasal com aspecto verrucoso. ${ }^{11} \mathrm{Em} \mathrm{2014,} \mathrm{Martins-Costa} \mathrm{relatou} \mathrm{outro} \mathrm{caso} \mathrm{com}$ apresentação facial simulando rosácea. ${ }^{12}$ Outros dois casos de esporotricose peri-orbitária foram publicados, em 2016 por Song et al ${ }^{13}$ e em 2007 por Sharma et al. ${ }^{14}$ A paciente do caso relatado, apresentou lesão nódulo-ulcerada na região de dorso nasal, supra labial e glabelar, com diagnóstico tardio, devido à baixa suspeição inicial do diagnóstico de esporotricose, mesmo em área hiperendêmica da doença, visto que a mesma negava contato com gatos.

O diagnóstico é baseado na suspeita clínica e epidemiológica, sendo complementado pelo exame histopatológico, micológico e sorológico. A histologia de uma lesão cutânea pode exibir infiltrado granulomatoso com microabcessos neutrofilicos e, em alguns casos, pode-se visualizar o agente etiológico, descrito como "corpos de charuto". A cultura, considerada "gold-standard", apresenta uma colónia branca membranosa que se torna enegrecida em semanas. Ainda que negativo neste caso, o teste ELISA (SsCBF) tem habitualmente uma boa relação clinico sorológico e pode ser utilizado para todas apresentações clínicas, apresentando uma sensibilidade de $90 \%$ e especificidade de $80 \%$. $^{3,15}$

O diagnóstico diferencial de esporotricose na região facial é extenso, devido ao grande pleomorfismo clínico. Devem ser consideradas outras micoses profundas, como paracoccidioidomicose, mucormicose, doenças neoplásicas, como carcinoma basocelular ou espinocelular, micobacterioses atípicas, pioderma gangrenoso, rosácea, entre outras. ${ }^{10,13}$

O arsenal terapêutico é diverso, incluindo tratamentos farmacológicos e não farmacológicos, sendo a escolha feita de acordo com a forma clínica, estado imunológico e contra-indicações de cada paciente. Os tratamentos farmacológicos incluem o itraconazol, terbinafina, iodeto de potássio e fluconazol, entre outros. Pode ser utilizada também a anfotericina $B$, sendo de escolha nas formas disseminadas ou gestantes com quadros graves. Já a principal medida não farmacológica é a termoterapia, mais utilizada nas formas cutâneas fixas e ou cutâneo linfáticas leves. Excisão cirúrgica ou debridamento da lesão sem a concomitância de um tratamento farmacológico não são indicados. ${ }^{15-18}$

\section{CONCLUSÃO}

Devido à grande incidência de esporotricose no Brasil, deve-se sempre ter como diagnostico diferencial tal doença. No caso relatado, paciente apresentou lesão nódulo-ulcerativa na região nasal, lábio superior e glabela, com progressão arrastada, sendo tratada previamente de forma inadequada 


\section{Caso Clínico}

devido ao diagnóstico incorreto. Apesar da paciente negar contato direto com gatos e a localização da lesão ser atípica para faixa etária adulta, por se tratar de uma cidade com grande incidência da doença é fundamental ter como suspeita diagnóstica a esporotricose, para que se inicie precocemente o tratamento correto, evitando complicações e sequelas desfigurantes.

Conflitos de interesse: Os autores declaram não possuir conflitos de interesse.

Suporte financeiro: $O$ presente trabalho não foi suportado por nenhum subsídio ou bolsa.

Confidencialidade dos dados: Os autores declaram ter seguido os protocolos do seu centro de trabalho acerca da publicação dos dados de doentes.

Protecção de pessoas e animais: Os autores declaram que os procedimentos seguidos estavam de acordo com os regulamentos estabelecidos pelos responsáveis da Comissão de Investigação Clínica e Ética e de acordo com a Declaração de Helsínquia da Associação Médica Mundial.

Consentimento dos Doentes: Obtido.

Conflicts of interest: The authors have no conflicts of interest to declare.

Financing Support: This work has not received any contribution, grant or scholarship.

Confidentiality of data: The authors declare that they have followed the protocols of their work center on the publication of data from patients.

Protection of human and animal subjects: The authors declare that the procedures followed were in accordance with the regulations of the relevant clinical research ethics committee and with those of the Code of Ethics of the World Medical Association (Declaration of Helsinki).

Patients consent: Obtained.

\section{REFERÊNCIAS}

1. Carrasco Zuber JE, Navarrete Dechent C, Bonificaz A, Fich F, Vial-Leterlier V, Berroeta Mauriziano D. Parte 1: micosis subcutâneas. Actas Dermo-Sifiliográf. 2016; 107: 806-15.

2. Reis BD, Cobucci FO, Zacaron LH, D'Acri, AM, Lima RB, Martins CJ. Sporotrichosis in an unusual location: a case report. An Bras Dermatol. 2015;90 (3 Suppl 1): S84-7.

3. Bernardes-Engemann $A R$, de Lima Barros $M$, Zeitune T, Russi DC, Orofino-Costa R, Lopes-Bezerra LM. Validation of a serodiagnostic test for sporotrichosis: a follow-up study of patients related to the Rio de Janeiro zoonotic outbreak. Med Mycol. 2015 53:28-33.

4. Araujo ML, Rodrigues AM, Fernandes GF, Camargo ZP, Hoog GS. Human sporotrichosis beyond the epidemic front reveals classical transmission types in Espírito Santo, Brazil. Mycoses. 2015;58: 485-90.
5. Barros MB, Schubach Ade O, do Valle AC, Gutierrez Galhardo MC, Conceição-Silva F, Schubach TM, et al. Cat-transmitted sporotrichosis epidemic in Rio de Janeiro, Brazil: description of a series of cases. Clin Infect Dis. 2004; 38:529-35.

6. Read SI, Sperling LC. Feline sporotrichosis. Transmission to man. Arch Dermatol. 1982;118:429-31.

7. Gremião ID, Menezes RC, Schubach TM, Figueiredo AB, Cavalcanti MC, Pereira SA. Feline sporotrichosis: epidemiological and clinical aspects. Med Mycol. 2015; 53:15-21.

8. Orofino-Costa R, Macedo PM, Bernardes-Engemann AR. Hyperendemia of sporotrichosis in the Brazilian Southeast: learning from clinics and therapeutic. Curr Fungal Infect Rep. 2015;9:220-8.

9. Rafal ES, Rasmussen JE. An unusual presentation of fixed cutaneous sporotrichosis: a case report and review of the literature. J Am Acad Dermatol. 1991; 25(5 Pt 2):928-32.

10. Mahajan VK, Sharma NL, Shanker V, Gupta P, Mardi K. Cutaneous sporotrichosis: unusual clinical presentations Indian J Dermatol Venereol Leprol. 2010;76:27680.

11. Bargman HB. Sporotrichosis of the nose with spontaneous cure. Can Med Assoc J. 1981;124:1027.

12. Martins-Costa GM, Bonamigo RR. Facial verrucous sporotrichosis in an adult during treatment for rosacea. Int J Dermatol. 2014;53: e80-e157.

13. Song JG, Song YB, Yun SY, Suh MK, Ha GY, Kim JR, et al. Cutaneous sporotrichosis presenting as clinical feature of facial cellulitis in an adult. Ann Dermatol. 2016;28:507-8.

14. Sharma NL, Mehta KI, Mahajan VK, Kanga AK, Sharma VC, Tegta GR. Cutaneous sporotrichosis of face: polymorphism and reactivation after intralesional triamcinolone. Indian J Dermatol Venereol Leprol. 2007;73:188-90.

15. Bernardes-Engemann $A R$, Orofino-Costa $R$, Miguens $B R$, Penha CV, Neves E, Pereira BA, et al. Development of an enzyme-linked immunosorbent assay for the serodiagnosis of several clinical forms of sporotrichosis. Med Mycol. 2005; 43:487-93.

16. Mahajan VK. Sporotrichosis: an overview and therapeutic options. Dermatol Res Pract. 2014;2014:272-376.

17. Kauffman CA, Bustamante B, Chapman SW, Pappas PG; Infectious Diseases Society of America. Clinical practice guidelines for the management of sporotrichosis: 2007 update by the Infectious Diseases Society of America. Clin Infect Dis. 2007;45:1255-6.

18. Machado T, Dantas C, Prohmann C, Silva L, Montes L, Gatti R, et al. Esporotricose na infância: Mimetizando Leishmanise: Evolução favorável com iodeto de potássio: Rev Soc Port Dermatol Venereol. 2017;75: 183-5. 